\title{
DI BALIK TOPENG HUDOQ, TERSIBAK CERITA ASAL USUL LAHIRNYA TARI HUDOQ
}

\author{
NURYASMI \\ SMA Negeri 2 Tenggarong, Jalan Pesut Rt VII Kelurahan Timbau, Kecamatan \\ Tenggarong, Kabupaten Kutai Kartanegara, Provinsi Kalimantan Timur \\ Email : nuryasmi2004@gmail.com
}

\begin{abstract}
ABSTRAK
Tari Hudoq Manugal pada masyarakat Suku Dayak Bahau di Kecamatan Tenggarong Kabupaten Kutai Kartanegara. Keaneragaman budaya yang ada di Indonesia merupakan kekayaan yang harus dijaga dan dilestarikan, termasuk yang ada di Kalimantan Timur, yaitu Tari Hudoq Manugal sangat perlu dikaji dan dipelajari dan selanjutnya dilestarikan sebagai kearifan lokal masyarakat suku Dayak Bahau di kecamatan Tenggarong Kabupaten Kutai Kartanegara. Penelitian ini bertujuan untuk mengetahui 1). Latar belakang atau asal usul lahirnya Tari Hudoq Manugal pada masyarakat Suku Dayak Bahau di Kecamatan Tenggarong Kabupaten Kutai Kartanegara. 2). Bentuk penyajian Tari Hudoq Manugal. Penelitian ini merupakan jenis penelitian kualitatif deskriptif. Informan dalam penelitian ini adalah kepala suku, pemangku adat, budayawan, pelatih dan penari. Pengumpulan data melalui studi pustaka, observasi, wawancara dan dokumentasi. Hasil penelitian menunjukkan bahwa,Tari Hudoq Manugal sudah ada sejak manusia ada, kepecayaan tersebut secara turun temurun dari nenek moyang masih dipercaya, tetapi ada juga yang berpendapat bahwa Hudoq merupakan hanya mitos, legenda, cerita atau kisah perkawinan antara mahluk gaib yang ada di dasar sungai dengan manusia ,yang di percaya dan di lestarikan dari generasi ke generasi. Tari Hudoq Manugal disajikan dalam bentuk kelompok dengan jumlah penari tidak terbatas, dalam bentuk penyajian sakral penari biasanya berjumlah sebelas orang, dalam bentuk ganjil. Ragam gerak ada 5 yaitu: Jiak, Jiak Lut, glek halu, jiak dong, dan kuwai. Adapun desain lantai yang digunakan dalam pertunjukan adalah garis lurus kemudian melingkar sampai akhir tarian. Tari Hudoq Manugal dibawakan oleh penari laki - laki dewasa karena kostumnya yang berat, dengan kostum busana hudoq dan topeng hudoq serta menggunakan properti tongkat kayu bagi pemimpin hudoq, ivung hudoq, Mandau, sunung, tabin, dan balun. Adapun iringan Tari Hudoq Manugal adalah gong dan gendang Panjang kurang lebih 2 meter (tuvung).
\end{abstract}

Kata Kunci : tari hudoq manugal, masyarakat suku dayak bahau

\section{PENDAHULUAN}

Indonesia memeliki berbagai tradisi yang unik dalam setiap perayaannya. Salah satunya adalah Tari Hudoq dari Kalimantan Timur. Tari adalah ekspresi perasan manusia yang diungkapkan lewat gerak ritmis dan indah yang telah mengalami stilisasi maupun distorsi (Soedarsono dalam Hadi, 2007 : 29). Tari lahir dari aktivitas masyarakat yang sedrhana, kemudian berkembang dan seterusnya melekat sehingga menjadikannya bagian yang tidak dapat dipisahkan dalam masyarakat. Seni Tari merupakan ciptaan manusia berupa gerak - gerak ritmis yang indah, menurut 
Sumandiyo (2005 : 13). Seni Tari merupakan gerak ekpresif (gerak maknawi) yang ditirukan dari gerakan burung, ombak, tumbuhan, maupaun runitas manusia sehari hari, seprti menanam padi, nelayan menangkap ikan dan gerak - gerak simbolis lainnya. Seni Tari adalah perwujudan suatu macam tekanan emeosi yang dituangkan dalam bentuk gerak seluruh anggota tubuh yang teratur dan berirama sesuai dengan musik pengiringnya menurut Sulistyo (dalam Zora Iriani, 2008 : 144). Selain itu terdapat pula unsur - unsur tari yaitu tubuh, gerak, irama, ekspresi dan ruang. Seni Tari yang berkembang di masyarakat dapat dibedakan menjadi tari tradisional dan tari modern. Pengertian tradisional dapat dipahami sebagai tata yang berlaku di sebuah lingkungan etnik tertentu yang bersifat turun temurun.

Berdasrakan pengrtian di atas, tari tradisional dapat diartikan sebagai sebuah tata cara menari atau menyelenggarakan tarian yang dilakukan oleh sebuah komunitas etnis secara turun temurun dari satu generasi ke generasi berikutnya. Secara etnisitas, tarian yang dikelompokkan pada tarian tradisional memiliki ciri - ciri tertentu pada motif, ragam, dan bentuk geraknya serta corak dan motif pakaian yang dikenakan penarinya. Tari tradisional yang berkembang di Indonesia, memiliki fungsi - fungsi ritual yang dimiliki oleh kelompok suku. Tari tradisional pada kelompok suku tertentu biasanya mengandung simbol - simbol, atau stilisasi dari gerakan yang dilakukan dan menjadi ciri khas suku yang bersangkutan. Tari tradisional di setiap daerah di Indonesia banyak mengalami perkembangan sehingga peran serta penata tari dan sanggar-sangar tari memungkinkan untuk menjaga dan melestarikan eksistensi tarian tradisional tersebut, agar tetap bertahan dan lestari untuk generasi berikutnya.

Tari tradisional adalah tarian yang tumbuh dan berkembang di wilayah atau komunitas sehingga menciptakan suatu identic budaya dari masyarakat yang bersangkutan. Dapat dikenal dari ciri - cirinya yang khas dan diakui dari wilayah asalnya. Ciri - cirinya dapat dilihat dari unsur gerak, tata rias, busana, spiritual, serta music pengiringnya, (Sumaryono,2006 : 54).

Bisa ditarik kesimpulan bahwa seni tari merupakan gerak - gerak ritmis dari anggota tubuh sebagai ekspresi dan pengungkapan perasaan dari penari yang di ikuti alunan musik pengiringnya. Jadi seni tari tidak hanya asal menggerakkan anggota tubuh, akan tetapi memiliki maksud dan makna tertentu yang ingin disamapaikan penari bagi penikmatnya. Tari merupakan salah satu cabang seni, yang telah tercipta sejak lama. Tari sebagai karya seni merupaka alat ekspresi dan sarana komonikasi seniman kepada orang lain (penonton/ penikmat). Sebagai alat ekspresi, tari mampu menciptakan untaian gerak yang dapat memmbuat penontonya atau penikmatnya peka terhadap sesuatu yang terjadi di sekelilingnya. Tari adalah sebuah ungkapan, pernyataan dan ekspresi dalam gerak yang memuat komentar- kometar mengenai realita kehidupan yang bisa merasuk ke relung hati penikmatnya ( Jazuli, 2008: 4 ).

Tari pertunjukan adalah tari yang ditampilkan untuk dilihat dan dinikmati serta dapat dihayati oleh orang lain (Soedarsono, 1986 : 7). Tari pertunjukan adalah karya tari oleh penciptanya dibuat atau disusun sebagai tari tontonan. Pada buku "Tari Tontonan", Sumaryono (2008: 17) memberikan pemahaman banyak hal tentang tari. Ia membuka kesadaran, wawasan, atau kepekaan kita dalam melihat suatu jenis kesenian tidak sekadar sebagai tontonan, tetapi juga sebagai pertunjukan yang menjelaskan banyak hal dari berbagai sisi kehidupan. 
Tari yang tergolong seni pertunjukan adalah, tari rakyat, Tari upacara, tari hiburan, yang sudah digarap menjadi sebuah tari pertunjukan. Tari pertunjukan diselenggarakan menurut waktu, tempat senimannya maupun penontonnya. Ada yang dipertunjukkan di lapangan, di gedung pertunjukan, semua diadakan berdasarkan keadaan dan kepentingan masyarakat (Soemaryono , 2006 : 24)

Masyarakat Suku Dayak Bahau memiliki keragaman budaya dan kesenian yang dilatar belakangi oleh agama Sang Aji ( agama kepercayaan Kahariangan). Kehidupan yang berdasarkan pada tradisi masih terus dilangsungkan, lengkap dengan upacara adat dan tarian dalam beberapa acara seperti menanam padi ( Manugal ). Kepercayaan tersebut menghadirkan berbagai kesenian tradisional seprti Tari Hudoq Manugal. Salah satu tari yang hingga saat ini masih hidup dan berkembang di masyarakat Suku Dayak Bahau adalah Tari Hudoq Manugal.

Di Kecamatan Tenggarong Kabupaten Kutai Kartanegara, Suku Dayak Bahau masih tetap eksis dan menjaga Tari Hudoq Manugal sebagai warisan leluhurnya serta menyadari sepenuhnya bahwa hal tersebut menjadi tanggung jawabnya untuk terus melestarikan dan menjaga perkembangannya.Pada awalnya Tari Hudoq Manugal merupakan sebuah seni yang tidak lepas dari kegiatan ritual dan sosial Suku Dayak Bahau.

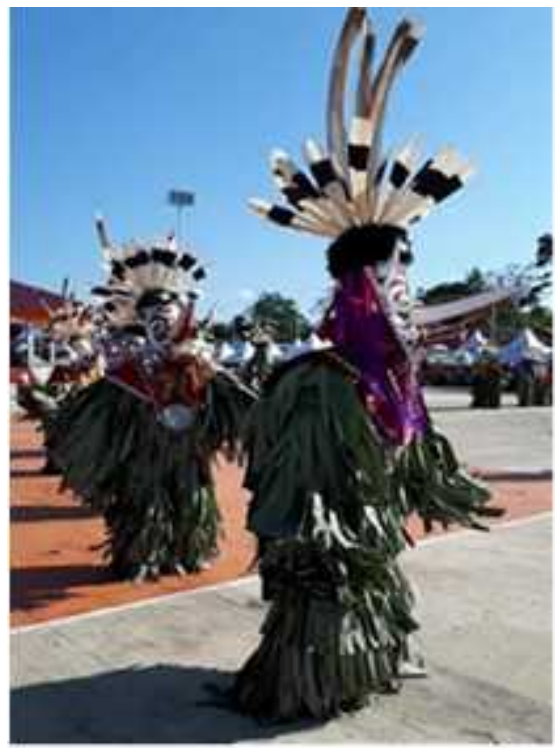

Gambar 1

Tari yang dalam dialek masyarakat Suku Dayak Bahau disebut Hudoq Manugal ini ditampilkan pada masa selesai menanam padi di ladang. Upacara ini dilaksanakan sebagai ungkapan rasa syukur, pengharapan dan perlindungan agar padi yang sudah di tanam tidak diganggu oleh hama perusak tanaman seperti tikus, burung, rusa, babi dan lain- lain agar hasilnya berlimpah ruah dan membawa kesejahteraan pada masyarakat. (W.BB.1).

Sejalan dengan perkembangan zaman, Tari Hudoq Manugal banyak mengalami perkembangan dari segi fungsi, tujuan pementasan maupun aspek- aspek lainnya. Bertolak dari hal tersebut diatas maka generasi pencinta seni dan generasi penerus perlu 
adanya kerja sama yang baik agar tari ini bisa dilestarikan dan tidak punah (W.LT. 2 :).

Didalam pelaksanaan upacara adat sesudah manugal atau menanam padi yang menggunakan topeng hudoq, merupakan suatu tari penjelmaan berupa jenis hewan dan ada pula yang berbentuk manusia. Masyarakat Dayak Bahau percaya bahwa lewat gerak - gerak yang ditarikan oleh penari Hudoq akan memepengaruhi alam dan menimbulkan suatu kesuburan bagi masyarakat yang mengadakan upacara adat tersebut. Adat yang dilaksanakan tersebut disebut" Pesta Hudoq" atau adat "Laliq Ugal".

\section{METODE PENELITIAN}

Metode yang digunakan penulis dalam penelitian ini menggunakan jenis penelitian deskriptif kualitatif. Infoemasi atau cerita sebagi sumber utama dlam penelitian ini. Informan dalam penelitian ini adalah kepala suku, pemangku adat, budayawan, pelatih, penari, dan pemerintah daerah setempat dan jajarannya dan masyarakat suku Dayak Bahau. Pengumpulan data melalui studi Pustaka, observasi, wawancara, dan dokumentasi.

Fokus penelitian ini adalah latar belakang atau asal usul lahirnya Tari Hudoq Manugal. Objek penelitian adalah, 1.) Latar belakang lahirnya Tari Hudoq yang dimaksudkan ialah asal usul atau pertimbangan yang menyebabkan Tari Hudoq Manugal diciptakan dan dipertunjukkan dalam kebudayaan masyarakat suku Dayak Bahau. 2). Bentuk penyajian Tari Hudoq Manugal, yang dimaksudkan adalah wujud, ragam gerak, pola lantai, kostum, dan musik pengiring dalam pertunjukan Tari Hudoq Manugal. Subjek penelitian adalah penari, pelatih, pemangku adat, kepala suku, budayawan, dan masyarakat suku Dayak Bahau yang tinggal di ujoh Bilang. Lokasi penelitian, pada acara diselenggarakannya Cross Border Festival Tari Hudoq Manugal di Desa Ujoh Bilang, Kecamatan Long Bagun, Kabupaten Mahakam Ulu, Kalimantan Timur.

\section{HASIL PEMBAHASAN}

\section{a) Asal Usul Tari Hudoq Manugal}

Tari Hudoq adalah Tarian Tradisional Kalimantan Timur yang menggunakan topeng sebagai perwujudan dari binatang, leluhur dan dewa. Tarian ini biasanya di tampilkan pada saat pembukaan lahan pertanian atau setelah menanam padi di lading. Menurut kepercayaan masyrakat khususnya masyarakt suku Dayak Bahau, tarian ini merupakan ritual permohonan kepada Tuhan agar hasil pertanian mereka di berikan hasil yang melimpah ruah (W. JL. 2).

Nama Tari Hudoq ambil dari kata hudoq yang berarti menjelma. Maka dalam tarian ini penari menggunakan topeng sebagai perwujudan dari hewan atau hama yang dianggap perusak tanaman seperti, tikus, gagak, monyet, babi, dan lainnya. Topeng yang melambangkan burung elang dianggap sebagai pelindung serta memelihara hasil panen masyarakat Dayak Bahau dan ada juga topeng manusia yang dilambangkan sebagai para leluhur atau nenek moyang mereka. 
Penari juga menggunakan baju yang terbuat dari kulit pohon yang dihiasi rumbai berwarna hiajau yang terbuat dari daun pisang atau daun kelapa. Baju ini menyibolkan dedaunan yang di harpkan terus menghijau agar tanaman yang mereka tanam tumbuh subur seperti yang di harapkan (W. DH. 3). Topeng yang digunakan adalah topeng yang terbuat dari kayu Jelatung dengan ukuran dan bentuk yang berbeda - beda sesuai dengan perwujudan yang ingin ditampilkan. Tidak ketinggalan, penutup kepala yang dihiasi dengan bulu burung enggang yang telah menjadi ciri khas dan memiliki arti khusus bagi masyarakat Suku Dayak Bahau. (TW.JL.4).

Terdapat beberapa pantangan yang berkaitan dengan penari Hudoq yaitu, penari Hudoq tidak boleh terkena siraman air saat menari. Jika penari terkena siraman air maka penari tersebut akan penyakit yang hanya bisa disembuhkan oleh orang yang sudah dirahmati kemanpuan mengobati penyakit di kampung itu. Pantangan lain adalah penonton tidak boleh memukul penari Hudoq, karena Hudoq adalah penjelmaan Roh atau Dewa. Imbasnya adalah penonton yang secara sengaja atau tidak sengaja memukul penari Hudoq, makai a akan ketulahan ( kualat ) dan akan sakit (TW. JL. 5).

Tari Hudoq Manugal hanya hanya bisa ditampikan pada upacara Manugal ( tanam padi ) dan tidak boleh ditampilkan pada upacara perkawinan atau upacara naik ayun. Jika ditampilkan diluar pada waktunya akan terjadi bencana kegagalan panen dan kampung akan di serang wabah penyakit atau kesialan (TW. JL. 6). Gerakan yang ditampilkan dalam tarian ini adalah perpaduan gearakan tangan dan kaki. Dengan badan tegak penari menggerakkan badan ke kanan dan ke kiri di setiap langkahnya. Tangan diayunkan ke atas dan kebawah sambal menepuk paha. Geraka kaki berjalan dengan diangkat dan menghentak ke tanah sehingga menimbulkan suara hentakan. Gerakan kepala hanya mengangguk, bila mulut pada topeng dapat di gerakkan maka topeng tersebutterlihat seperti berbicara (TW. LJ. 6).

Dalam Tari Hudoq ini, penari bergerak dalam lingkaran barisan. Penari bergerak dari satu sudut ke sudut lain sampai ke empat sudut tersentuh. Kemudian penari dudk bersila dengan berbaris memanjang sambal memanggil roh. Pada saat pemanggilan roh, roh tersebut mulai merasuki mereka seperti kesurupan , kemudian para penari kembali menari seperti semula. Setelah itu, roh yang merasuki mereka tadi akan keluar dari tubuh mereka dan meninggalkannya.

Dalam pertunjukan Tari Hudoq memang terlihat bernuansa mistis. Dalam pelaksanaan ritual pawang atau pemimpin upacara memulai dengan pembacaan mantra dengan sesaji yang sudah dipersiapkan. Pada saat penari duduk berbaris pawang pun menaburkan beras kuning di kepala para penari sebagai tanda di mulainya acara. setelah itu penari kembali menari dengan iringan musik tradisional Suku Dayak Bahau. Saat penari kesurupan, pawang menyampaikan pesan kepada roh tersebut dengan mengucapkan mantra. Maksud dari mantra tersebut adalah untuk meminta agar roh tersebut menjaga tanaman mereka dan melindungi penduduk desa dari segala mara bahaya.

Pertujukan ini bisa berlangsung selama satu hari dan bahkan lebih. (TM. JL. 7). Seiring perkembangannya Tari Hudoq ini tidak hanya di tampilkan dalam berbagai perayaan budaya masyarakat Kalimantan timur, tetapi sebagai hiburan dengan bebagai modifikasi dan keativitas dalam pertunjukan. Dari hasil wawancara dengan pelaku 
seni, budayawan, pemangku adat, pemerintah terkait, pelatih tari, penari dan masyarakat.

Lahirnya Tari Hudoq tidak lepas dari mitos yang terdapat dan berlaku bagi Suku Dayak Bahau, dalam mitos diharuskan bagi mereka untuk memberikan persembahan kepada roh - roh tertentu yang diyakini dapat membawa keselamatan bagi kehidupan manusia atau sebaliknya dapat menimbulkan bencana. Roh - roh tersebut menampakkan dirinya dalam bentuk atau jenis binatang tertentu seperti burung enggang, rusa, babi, monyet, buaya dan sebagainya. Oleh karena itu dikeramatkanlah jenis binatang tersebut dalam bentuk topeng Hudoq. (TM :JL. 8). Hudoq adalah topeng, Hudoq adalah jelmaan, menurut bahasa Suku Dayak Bahau, Tari Hudoq adalah tarian topeng, jelmaan dari roh. Ini merupakan sebuah cerita tentang penghormatan Suku Dayak Bahau kepada bumi dan alam. Tentang orang - orang yang percaya bahwa restu leleuhur menjadi keutamaan untuk tanah yang subur. ( W.BB.9).

Setelah 10 hari tanam padi (manugal), diumumkanlah bahwa akan dilaksanakan pesta Hudoq Manugal, maka semua masyarakat sudah sibuk mengumpulkan bahan makanan dan bahan untuk ritual sebelum acara dimulai. Bahan - bahan yang disampaikan atau dipersembahkan sebelum pelaksanaan upacara adat ini terdiri dari: telur ayam kampung, piring putih, beras putih, gelang manik, kain putih, telur ayam kampung. Penari tidak terbatas jumlahnya, kecuali jika pesta Tari Hudoq Ritual maka jumlah penari harus ganjil, biasanya terdiri dari 11 orang, tapi pada pesta tari Hudoq Manugal tidak ada batasan jumlah, umur, atau jenis kelamin. Yang jelas, semua masyarakat yang mau ikut menari diperbolehkan. Karena tari ini hanya berfungsi sebagai tari pertunjukan dan hiburan, bukan ritual keagamaan ( W. BB. 10 ).

Dalam Tari Hudoq ini penari bergerak dalam lingkaran barisan. Penari bergerak dari satu sudut ke sudut lain sampai ke empat sudut tersentuh. Kemudian penari duduk bersila dengan berbaris memanjang sambil memanggil roh, roh tersebut mulai merasuki mereka seperti kesurupan. Kemudian para penari Hudoq kembali menari seperti semula dan setelah itu duduk Kembali. Setelah itu, roh yang merasuki mereka tadi akan keluar dari tubuh mereka dan meninggalkannya. Dalam pertunjukan Tari Hudoq Manugal memang terlihat bernuansa mistis. Dalam pelaksanaan ritual tersebut pawang atau pemimpin upacara memulai dengan pembacaan mantra dengan sesaji yang sudah di persiapkan. Saat para penari Hudoq duduk barbaris, pawang pun menaburkan beras kuning di kepala para penari sebagai tanda di mulainya acara. Setelah itu para penari pun menari dengan di iringi musik tradisional khas Suku Dayak Bahau yaitu Tuvung ( alat musik gendang Panjang kurang lebih 2 meter ) dan gong. Sebagian dari masyarakat zaman dahulu percaya, bahwa saat dilaksanakannya Tari Hudoq Manugal, orang yang sakit dapat sembuh apabila terkena kibasan kostum penari Hudoq tersebut. ( W. DL.11). 


\section{b) Cerita I Tari Hudoq Manugal}

Himpunan tulisan legenda Tari Hudoq Manugal ini bermula dari adanya cerita yang mengisahkan jika tarian ini berasal dari legenda raja Modang yang menikah dengan seorang putri kerajaan. Ada yang mengatakan laki - laki tersebut barnama Heleang Hebeung, sedangkan si putri adalah Selau Sen Yeang. Putri tersebut adalah keturunan dewa kerajaan Apau Lagaan (khayangan), yang berasal dari dasar pusaran sungai Mahakam. Perkawinan mereka melahirkan anak yaitu Buaq Selo. Suatu ketika, Heleang Hebeung pernah menyaksikan tari dari warga di Apau Lagaan sebagai hiburan. Mereka berasal dari dasar sungai. Mereka diundang dan diminta oleh Selau Sen Yeang, untuk menari dengan meriah. Heleang Hebeung begitu antusias dan kagum dengan mereka.

Mereka menari dengan gerakan, bunyi dan karakter masing - masing. Semakin lama menari, semakin tampak karakter asli dari mereka. Heleang Hebeung menjadi ketakutan setelah melihat karakter asli para penari yang menyeramkan. Heleang Hebeung sebagai manusia, merasakan kehidupannya yang tidak seperti para dewa. Ia merasa tidak betah dan memutuskan berpisah dengan istri dan anaknya, untuk kembali ke dunia manusia. Selau Sen Yeang pernah berkata saat perpisahan dengan suaminya, bahwa jika ia ingin kembali atau berhubungan dengan mereka (yang berada di Apau Lagaan), cukup dengan memanggil melalui upacara adat.

Heleang Hebeung pun menceritakan kisah para penari yang berubah menyeramkan itu, pada warga di desanya, kampung Leham Kejin. Untuk mengenang istrinya di Apau Lagaan, ia meminta para warga untuk membuat topeng karakter yang mirip denga apa yang pernah dilihatnya dulu di Apau Lagaan. Heleang Hebeung disebut - sebut sebagai pencetus upacara Tari Hudoq dengan tarian bertopeng berbagai karakter.

Dari situlah Suku Dayak Bahau meyakini bahwa ada dunia selain kehidupan manusia. Mereka juga meyakini Topeng Hudoq adalah benda sakral. Mereka yakin ada sosok selain manusia, dengan kekuasaan lebih tinggi dan menjadikan Topeng Hudoq sebagai sarana kemunculannya. ( TW. JL.12).

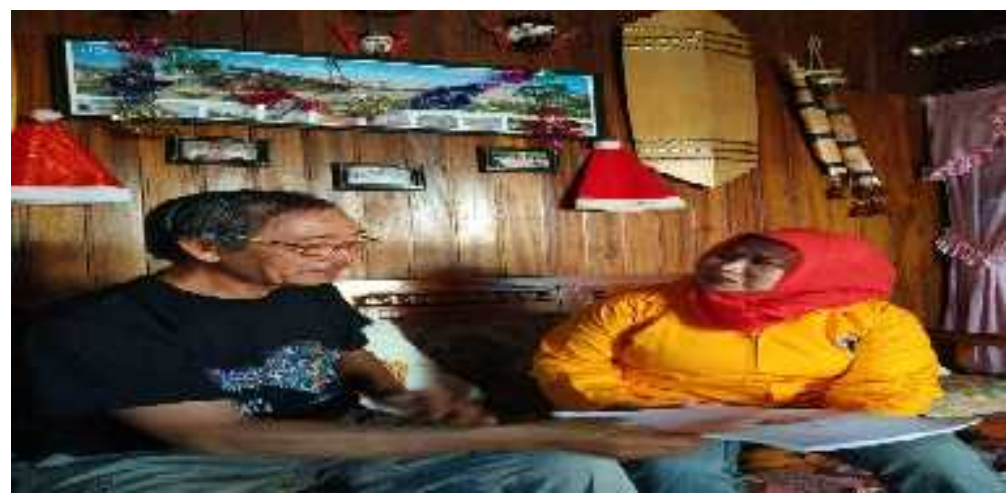

Gambar 2. Wawancara Dengan Budayanawan JL

Dokumentasi pribadi (Nuryasmi) 


\section{c) Cerita II Tari Hudoq Manugal}

Pada Suku Dayak Bahau, ada satu tradisi tahunan yang dilakukan setiap musim tanam. Tujuannya untuk mengenang jasa para leluhur. Mereka yakin jika saat musim tanam, roh para leluhur hadir untuk membimbing dan mengawasi garis keturunannya. Para leluhur berasal dari Asung Luhung (Ibu Besar), yang turun dari langit di kawasan hulu sungai Mahakam Apo Kahayan. Ibu Besar dengan kekuatan seperti dewa, bisa memanggil roh baik dan roh jahat. Dia juga yang menugaskan roh - roh yang disebut Jeliwan Tok Hudoq, untuk menemui manusia. Wujudnya yang menyeramkan, membuatnya harus menyamar dengan pakaian manusia setengah burung. Mereka membawa kabar baik. Mereka memberi barbagai benih dan tanaman obat - obatan kepada manusia di bumi.

Hudoq pun melekat dalam kehidupan adat Suku Dayak Bahau. Setiap datang musim tanam atau yang disebut Nugal, (tanam) tradisi Hudoq selalu dijalankan. Mereka diliputi ketakutan jika tidak melakukannya, justru membuat wabah penyakit atau malah gagal panen. Upacara Hudoq Manugal rutin dilaksanakan setiap Oktober sampai November. Suku Dayak Bahau meyakini, saat awal bulan - bulan tersebut adalah waktu di mana roh para dewa atau leluhur datang ke bumi, untuk melindungi dan membantu manusia. Walaupun secara ilmu - ilmu pasti, bulan Oktober sampai November adalah masa - masa kemungkinan terjadi gagal panen, penyerangan hama hingga musim kemarau panjang. Tidak hanya ritual tahunan Hudoq yang dilaksanakan di setiap desa. Setiap 5 tahun sekali, dilaksanakan pula ritual Hudoq besar. Ritual Hudoq wajib diawali dengan upacara sakral Napoq.

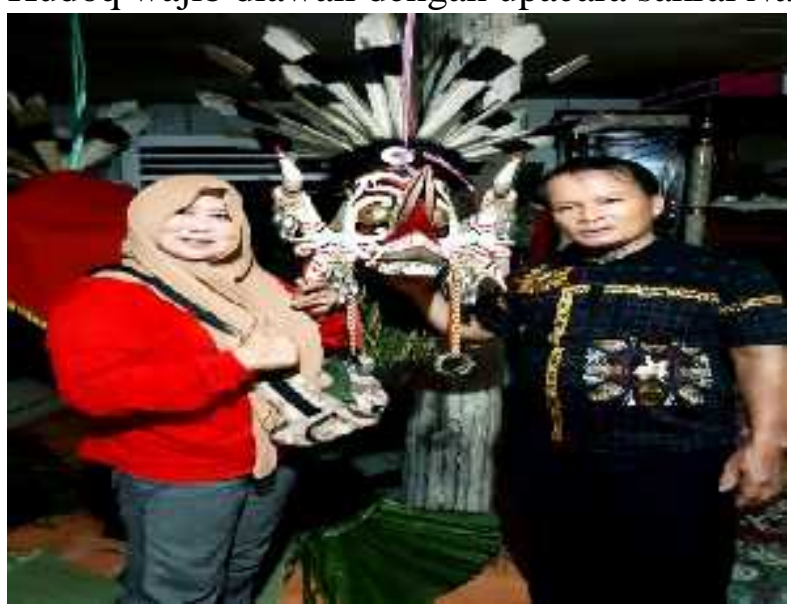

Gambar 3. Wawancara Dengan Narasumber Utama. DH. kepala suku Dayak Bahau dan pemangku adat)

Sejalan dengan perkembangan zaman, Tari Hudoq Manugal banyak mengalami perkembangan dari segi fungsi, tujuan pementasan maupun aspek- aspek lainnya. Bertolak dari hal tersebut diatas, maka generasi pencinta seni dan generasi penerus perlu adanya kerja sama yang baik agar tari ini bisa dilestarikan dan tidak punah ( Lusia Tuco). 
Tari Hudoq Manugal mempunyai fungsi sebagai:

1. Sebagai Sarana upacara, jenis tari ini bukan penyajian keindahan semata, melainkan juga kekuatan yang dapat mempengaruhi atau mengatur sesauai dengan maksud yang dikehendaki, (Amir Rokhyatmo, 1986: 7). Tari upacara banyak hidup dan berkembang pada masyarakat primitif.

2. Sebagai sarana hiburan, Tari hiburan atau tari pergaulan sering pula disebut tari gembira yang merupakan tarian yang cenderung hanya menitik beratkan pada kepuasan pelakunya sendiri atau semata - mata bukanlah menitik beratkan pada segi artistiknya, (Rusliana, 1986: 74). Menurut Soedarsono, tari hiburan adalah dimana titik berat pada tarian tersebut bukanlah keindahan, tetapi ditujukan pada segi hiburan, dan umumnya merupakan tarian pergaulan.

3. Sebagai sarana pertunjukan, tari pertunjukan adalah tari yang ditampilkan untuk dilihat dan dinikmati serta dapat dihayati oleh orang lain, (Amir Rakhyatmo, 1986: 77). Tari pertunjukan adalah tari yang menitikberatkan pada segi keindahannya bukan pada segi hiburannya. Semua diadakan berdasarkan keadaan dan kepentingan masyarakat, (Sumaryono, 2006: 24).

Begitu pula dengan Tari Hudoq Manugal, hanya bisa dipertunjukkan pada waktu waktu tertentu, yaitu selepas masa menanam padi (Manugal) di ladang. Tari Hudoq Manugal dilakukan dengan tujuan menunjukkan rasa syukur atas selesainya menanam padi dan memohon dan berharap mendapatkan hasil penen yang berlimpah ruah serta mendapatkan kesejahteraan dan kemakmuran bagi masyarakat.

\section{d) Bentuk Penyajian Tari Hudoq Manugal}

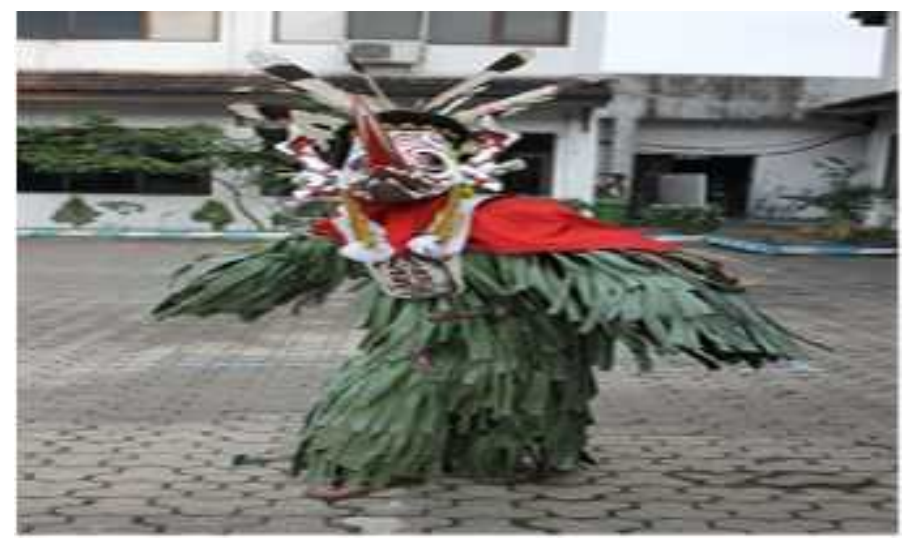

Gambar 4. Gerakan Tari Hudoq Manugal

Ada 5 ragam gerak dalam Tari Hudoq Manugal, yaitu Jiak, Jiak Lut, Glek Halu Jiak dong dan Kuwai (Lasah Juno : 2020) :

1. Jiak, (hentakan kaki kanan pertama melangkah). Gearakan ini bermakna permohonan untuk Sang Pencipta agar diberi keselamatan dan kesejahteraan untuk warga masyarakat yang baru menanam padi, dan hasilnya melimpah. 
2. Jiak Lut, (Kaki menghentak dengan tumit). Gerakan ini bermakna untuk mengusir hama penyakit agar tidak menyerang tanaman padi.

3. Glek Halu, (gerak mengguk patah - patah). Gerak ini bermakna permohonan perlindungan kepada Sang Pencipta dari segala malapetaka.

4. Kuwai, (kombinasi gerak kaki dan tangan, berulang dan berayun ke atas dan ke bawah). Gerakan ini bermakna ungkapan rasa syukur, senang, atas selesainya bertanam padi (manugal), dan berharap hasil panen nanti berlimpah ruah.

5. Jiak Dong, (Gerakan tangan menggelantung mengikuti arah badan). Gerakan ini bermakna, Gerakan ke kanan bermakna mengambil kebaikan, Gerakan ke kiri membuang bala atau membuang sial. Dahulukan tangan kanan setiap memulai bekerja, dan tangan kiri mengakhirinya.

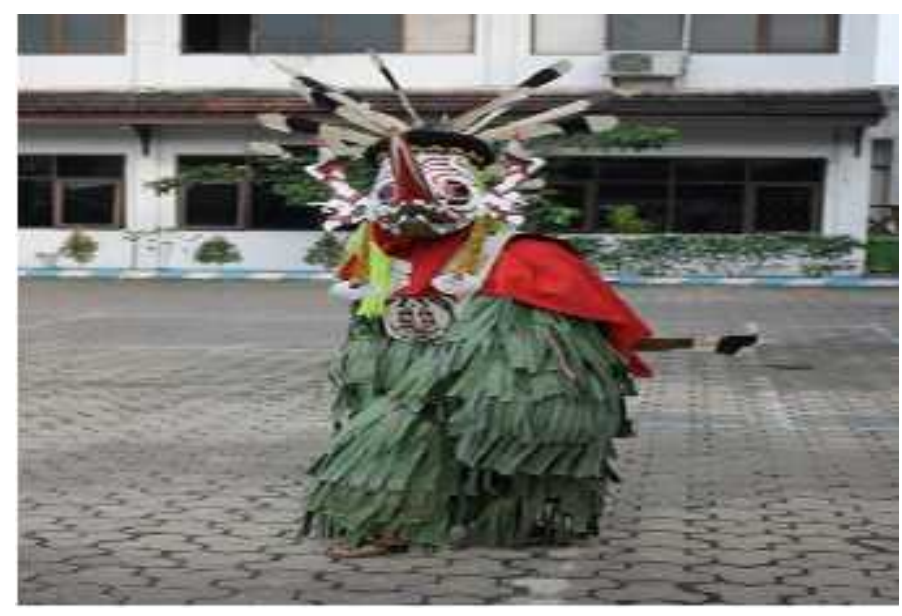

Gambar 5. Gerak Jiak Tari Hudoq Manugal

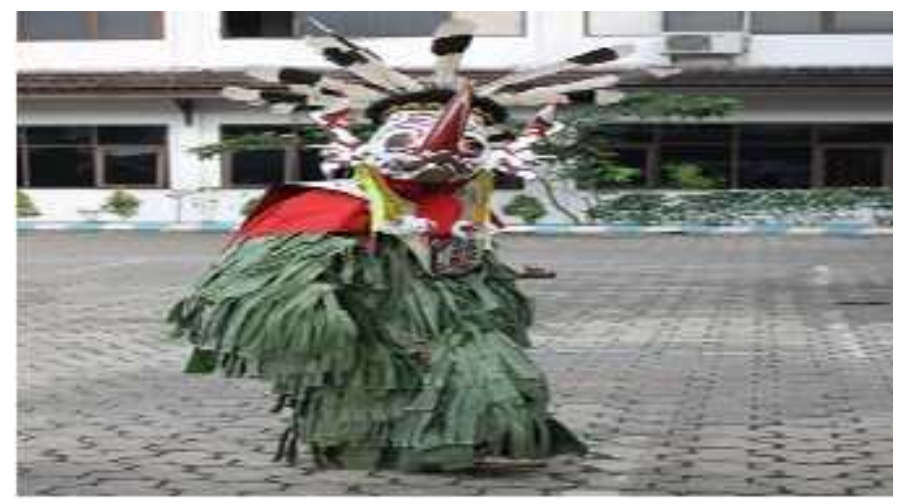

Gambar 6. Gerak Jiak Lut 


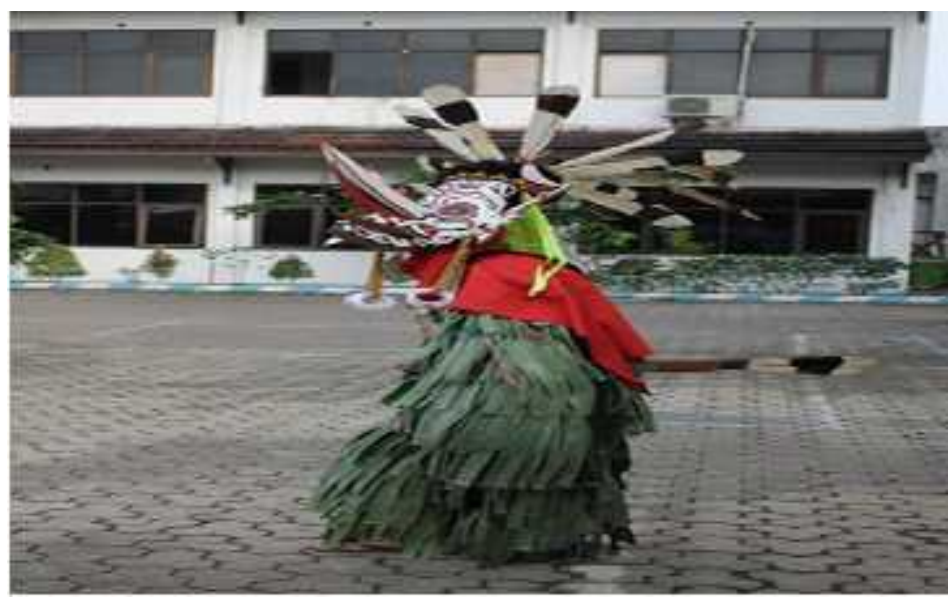

Bambar 7. Gerak Glek Halu Tari Hudok Manunggal

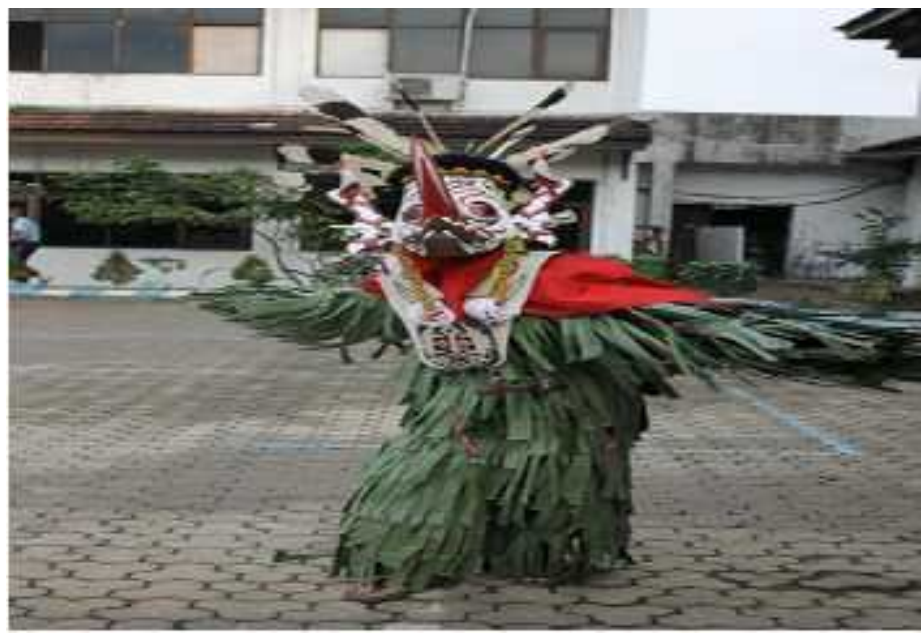

Gambar 8. Gerak Kuwai Tari Hudok Manunggal

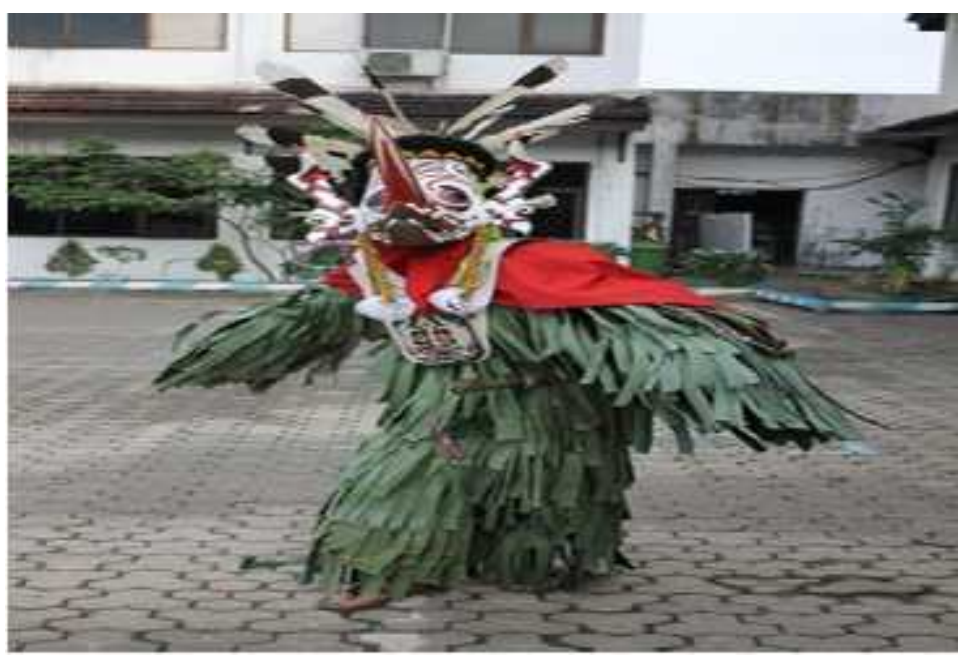

Gambar 8. Gerak Jiak dong Hudok Manunggal 


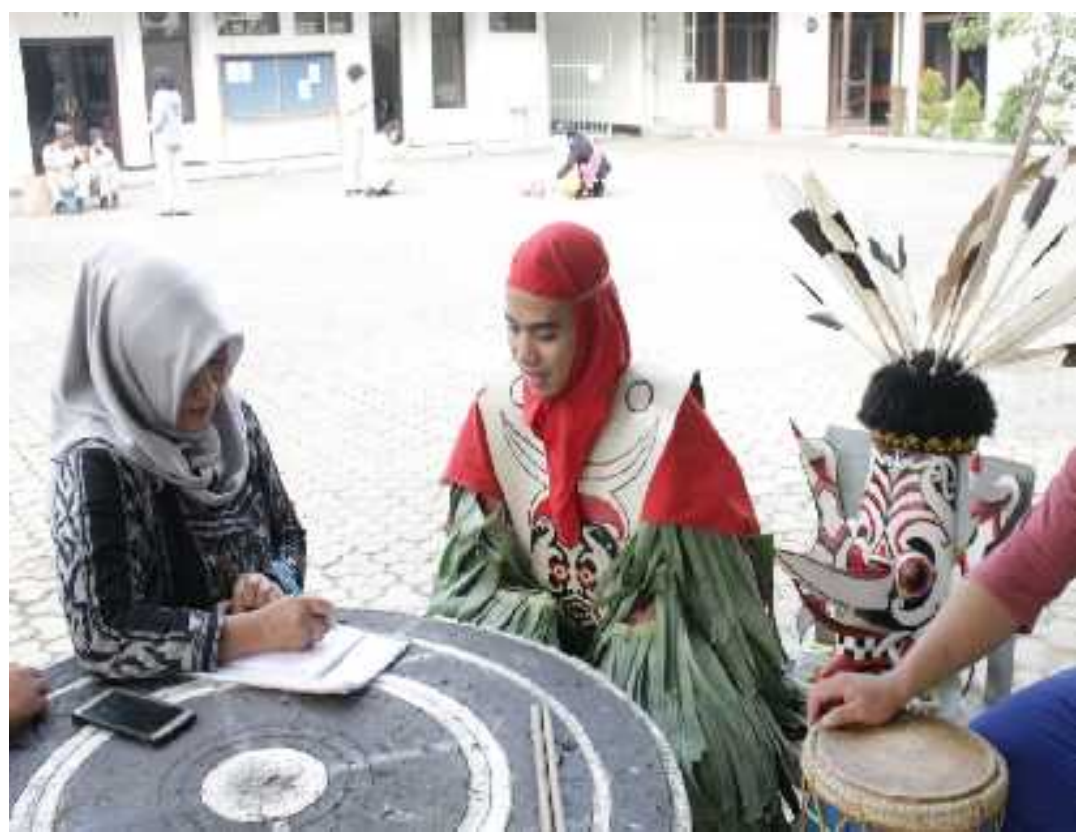

Gambar 9. Dokumentasi Bersama Penari tari Hudok Manunggal

Dalam pertunjukan Tari Hudoq Manugal, gerakan yang ditampilkan dalam tarian ini adalah perpaduan gerakan tangan dan kaki. Dengan badan tegak penari menggerakkan badan ke kanan dan ke kiri di setiap langkahnya. Tangan di ayunkan ke atas dan ke bawah sambil menepuk paha. Gerakan kaki berjalan dengan di angkat dan menghentak ke tanah sehingga menimbulkan suara hentakan. Gerakan pada kepala hanya mengangguk, bila bagian mulut pada topeng tersebut dapat di gerakkan maka topeng tersebut terlihat seperti berbicara. ( Narsum : N Lasah NJuno)

\section{e) Pola Lantai Tari Hudoq Manugal}

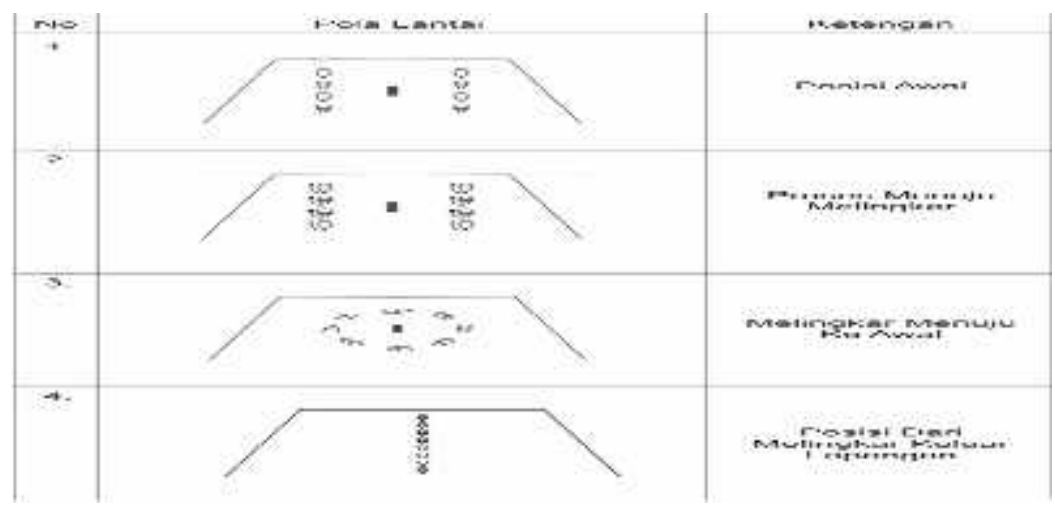

Gambar 10. Pola Tari Hudoq Manunggal 


\section{f) Pencapaian Tari Hudoq Manugal}

1. Oleh Kemenpar festival Tari Hudoq Manugal menjadi salah satu event Cross Border andalan Kementrian Pariwisata RI. Untuk mengundang wisatawan asing di daerah perbatasan. Bahkan Pemkab Mahakam Ulu sudah menetapakan jika mulai tahun 2018, Hudoq menjadi agenda wisata tetap tahunan. Tepatnya digelar setiap tanggal 20 - 30 oktober.

2. Di bulan November 2017 lalu, berhasil dipecahkan Record Muri tari Hudoq sebanyak 1000 penari, di Samarinda. Pada Oktober 2018, Bupati Mahakam Ulu, Bonifasius Belawan menerima sertifikat dari meseum rekor MURI. Catatan pementasan terbanyak untuk pertama kalinya dalam sejarah tari Hudoq yang dibawakan oleh 2.230 penari. Kabupaten Mahakam Ulu, Kalimantan Timur menjadi saksi penorehan rekor tersebut.

3. Pada tanggal 24 - 25 Oktober 2019, tari Hudoq Manugal Mahulu kembali memecahkan Rekor MURI. Kali ini, tercatat sebagai Tari Hudoq 24 jam tanpa henti. Masayarakat menari Hudoq secara bergantian tanpa henti, di lapangan Ujoh Bilang, Mahakam Ulu. Tari di mulai dari hari Kamis jam 20.00 WITA sampai dengan Jum'at jam 20.00 WITA.
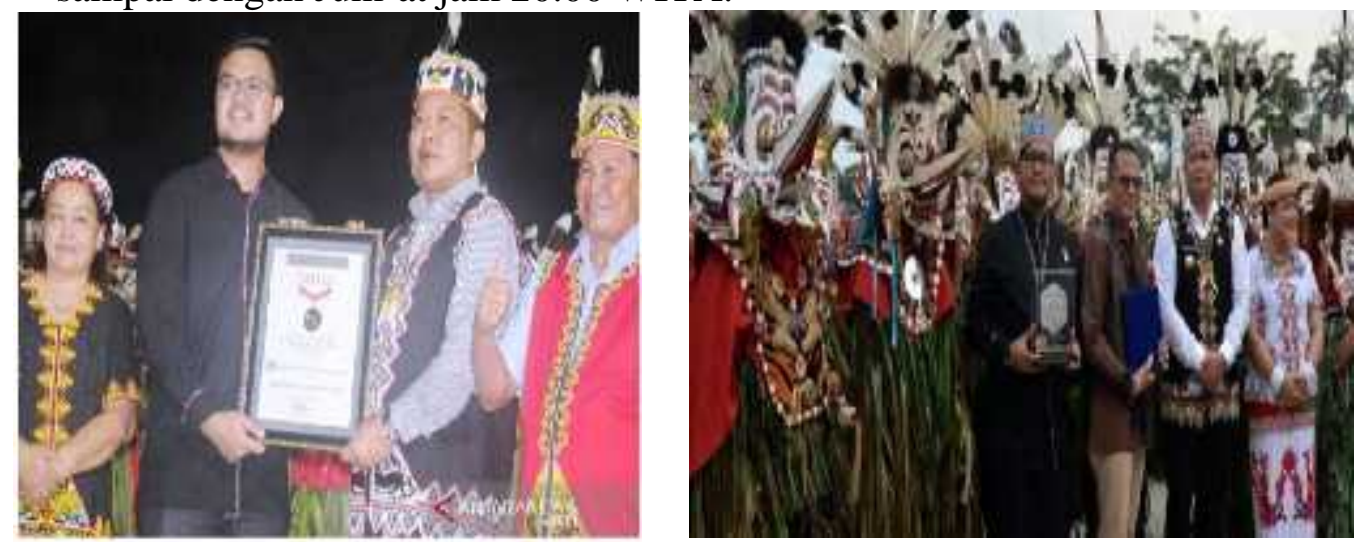

Gambar 11. Rekor MURI tercatat sebagai Tari Hudoq 24 jam tanpa henti.

\section{KESIMPULAN}

Berdasarkan hasil penelitian dan analisis data melalui observasi, wawancara, dan dokumentasi, maka dapat disimpulkan:

1. Tari Hudoq Manugal merupakan tari upacara syukuran atas selesainya menanam padi (Manugal), sebagai bentuk permohonan doa agar padi yang sudah di tanam mendapat perlindungan dari hama perusak padi, dan menghasilkan padi yang berlimpah ruah untuk kesejahteraan masyarakat. Tari Hudoq Manugal ada sejak bumi ini ada sejak manusia lahir ke bumi. Tari ini merupakan warisan turun temurun, kepercayaan itu diyakini sampai sekarang. Lahir dari titisan Dewa yang ada di khayangan yang disebut sebagai Ibu Besar. Untuk media Pendidikan dimana dari semua gerakan Tari Hudoq Manugal memberikan petuah yang mengajarkan 
tentang kesatuan dan persatuan agar masyarakat taat kepada aturan - aturan yang telah ditetapkan oleh para penganut agama.

2. Bentuk penyajian Tari Hudoq Manugal,

Dilaksanakan di arena terbuka seperti lapangan, di ladang, dan di halaman agar penonton dapat ikut menari dan bergembira. Ragam gerak Tari Hudoq Manugal ada 5 yaitu: Jiak, Jiak lut, Glek Halu, Kuwai, Jiak Dong. Ragam gerak dan musik masih tetap dipertahankan kesakralannya, tradisional, mistik, meskipun pengaruh perkembangannya selalu datang.

a) Desain Lantai Tari Hudoq Manugal menggunakan garis lurus pada awal pertunjukan untuk masuk ke dalam arena, kemudian membentuk lingkaran sampai akhir pertunjukan. Pola lantai melingkar mengandung kekeuatan sakral dan dipercaya dapat mempengaruhi kesuburan pada ladang pertanian serta keselamatan bagi warga masyarakat.

b) Kostum (tutur) yang menggunakan daun pisang atau daun kelapa yang berwarna hijau, memiliki makna kesuburan, kesejukan, keabadian, keselamatan dan kesuksesan baik dikaitkan dengan kehidupan padi maupun kehidupan manusia yang tumbuh dari kecil hingga dewasa.

c) Topeng Hudoq, melambangkan kekuatan yang sakral dalam upacara dan sebagai bentuk komunikasi serta penghormatan kepada karakter - karakter roh leluhur dan dewa - dewa yang membantu melindungi padi dan manusia.

d) Bagi masyarakat Dayak Bahau, tarian ini menggambarkan etika yang sangat konrit mengenai hubungan manusia dan alam lingkungan sekitarnya, serta manusia dengan roh - roh leluhur, serta mencerminkan kehidupan sosial masyarakat yaitu sikap penghormatan terhadap nilai - nilai kehidupan yang diajarkan para leluhur bahwa nilai kebersamaan, nilai kekeluargaan dan tanggung jawab sangat dijunjung tinggi oleh masyarakat Suku Dayak Bahau. Bersatu padu dan berusaha mempertahankan dan melestarikan budaya yang dijunjung tinggi dan dipercaya turun temurun dari nenek moyang meraka, yaitu Tari Hudoq Manugal ini dan berusaha untuk melestarikannya.

Semoga generasi muda di jaman mileneal ini masih ada yang berniat memelihra dan melestarikan tarian dan budaya lainnya demi kemajuan dan keragaman budaya di Indonesia.

\section{DAFTAR PUSTAKA}

Departemen Pendidikan dan Kebudayaan, 1994. Sejarah Kebudayaan Kalimantan. Jakarta : CV, Dwi Jaya Karya.

Hadi,, Sumandiyo,Y. 2007. Kajian Tari Teks dan Konteks. Yogyakarta: Pustaka Book Publisher. Yogyakarta.

Meleong, L,J. 2009. Metodologi penelitian Kualitatif. Remaja Rosdakarya. Bandung.

Dana, I wayan. 2010. Menjelajah Jejak Topeng dalam Budaya Indonesia dari masa ke masa. Dalam Pidato npengukuhan Jabatan Guru Besar pada fakultas Seni Pertunjukan Instutut seni Indonesia Yogyakarta. 
Murgianto, Sal. 2004. Tradisi Inovasi “ Bbeberapa Masalah Tari Di Indonesia. Jakarta: Wedatamawidyasastra.

Proyek Pusat Pengembangan Kebudayaan Kalimantan Timur (1977), Kumpulan Naskah Kesenian Tradisional Kalimantan Timur (Samarinda: Proyek Penerbitan Buku Bacaan dan Sastra Indonesia dan Daerah), p. 219.

Sumaryono. 2006. Tari Tontonan “Buku Pelajaran Kesenian Nusantara”. Lembaga Pendidikan Seni Nusantara. Jakarta.

Wardana R. M, Wisnoe. 1990. Pendidikan Seni Tari Bagi Guru SMA. Departemen Pendidikan dan Kebudayaan.

Rusliana, Iyus. 1986. Pendidikan Ksenian“ SENI TARI I “. Bandung. 1977.

E. Sumaryono. 1993. Hermeneutik, Sebuah Filsafat dalam Seni, Yogyakarta : Penerbit Kanisius

Daryono, Tari dan Pengendalian Diri, Jurnal Greget Institut Seni Indonesia, Jakarta 2010 hlm 13.

Jazuli, M. 2001. Paradikma Seni Pertunjukan.Yogyakarta : Yayasan LenteraBudaya.

Soedarsosno, RM. 1998. Seni Pertunjukan Indonesia . Jakarta : DijenPendidikan Tinggi Depdikbud. 